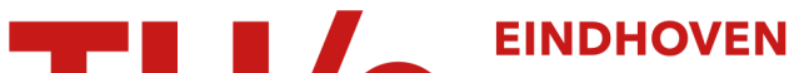

\section{Fault-Tolerant Control of Series Connectable Modular Full- Bridge Inverter Mitigating Open Switch Faults}

\section{Citation for published version (APA):}

Arrozy, J., Retianza, D. V., Duarte, J. L., \& Huisman, H. (2020). Fault-Tolerant Control of Series Connectable Modular Full-Bridge Inverter Mitigating Open Switch Faults. In 2020 22nd European Conference on Power Electronics and Applications, EPE 2020 ECCE Europe [9215820] Institute of Electrical and Electronics Engineers. https://doi.org/10.23919/EPE20ECCEEurope43536.2020.9215820

DOI:

10.23919/EPE20ECCEEurope43536.2020.9215820

Document status and date:

Published: 01/09/2020

\section{Document Version:}

Accepted manuscript including changes made at the peer-review stage

\section{Please check the document version of this publication:}

- A submitted manuscript is the version of the article upon submission and before peer-review. There can be important differences between the submitted version and the official published version of record. People interested in the research are advised to contact the author for the final version of the publication, or visit the $\mathrm{DOI}$ to the publisher's website.

- The final author version and the galley proof are versions of the publication after peer review.

- The final published version features the final layout of the paper including the volume, issue and page numbers.

Link to publication

\section{General rights}

Copyright and moral rights for the publications made accessible in the public portal are retained by the authors and/or other copyright owners and it is a condition of accessing publications that users recognise and abide by the legal requirements associated with these rights.

- Users may download and print one copy of any publication from the public portal for the purpose of private study or research.

- You may not further distribute the material or use it for any profit-making activity or commercial gain

- You may freely distribute the URL identifying the publication in the public portal.

If the publication is distributed under the terms of Article 25fa of the Dutch Copyright Act, indicated by the "Taverne" license above, please follow below link for the End User Agreement:

www.tue.nl/taverne

Take down policy

If you believe that this document breaches copyright please contact us at:

openaccess@tue.nl

providing details and we will investigate your claim. 


\title{
Fault-Tolerant Control of Series Connectable Modular Full-Bridge Inverter Mitigating Open Switch Faults
}

\author{
Juris Arrozy, Darian V. Retianza, Jorge L. Duarte, Henk Huisman \\ Eindhoven University of Technology \\ Eindhoven, The Netherlands \\ E-Mail: j.arrozy@tue.nl
}

\section{Acknowledgements}

This paper is part of the ModulED project that has received funding from the European Union's Horizon 2020 research and innovation programme under grant agreement No 79953.

\section{Keywords}

«faults», «fault tolerance», «fault handling strategy», «multiphase drive», «control of drive»

\begin{abstract}
This paper proposes the fault-tolerant control of a series connectable modular full-bridge inverter in case of an open switch fault. The faulty main switch is detected and identified by comparing the value of the measured phase node output voltage with the PWM signal generated for the respective phase leg. The series switch fault is detected and identified by comparing the measured output voltage of the phase legs connected by the series switch with a reference value. The post-fault control following an open main/series switch fault is realized by modifying several reference values in the healthy control system and is validated for several fault scenarios.
\end{abstract}

\section{Introduction}

Along with the recent growing interest in the development of electric vehicles, there has been a subsequent increasing attention to the power electronics circuit used to drive the electric motor. This is observed in [1], where it is argued that an efficient power electronics system is necessary to maximize the range of electric vehicles. Another study also shows how the power electronics drive topology selection influences the performance of the electric machine [2].

One of the major challenges in the power electronics for electric vehicle application is the reliability of the semiconductor switches, since their malfunction might halt the operation of the drive system. An industry-based survey given in [3] shows that the semiconductor switch is the most fragile component, especially in the motor drive applications. Thus, several approaches have been investigated to address the reliability issue in the semiconductor device.

In general, the approaches are divided into two categories. The first category is the preventive approach. In [4] it is implied that the lifetime of the switch depends mainly on its thermal swing. Thus, the common feature of this approach is to minimize the thermal swing by using various methods such as active gatedriving [5], switching frequency control [6], or combinations of both [7].

The second category is dubbed fault-tolerant approach. In this approach, the system is expected to be able to operate in an acceptable manner after experiencing a fault. Reviews on fault-tolerant three-phase inverter topologies were included in $[8,9]$. The series connectable modular full-bridge inverter analyzed in this paper, first introduced in [10] (although intended for driving six-phase surface-mounted permanent magnet synchronous motor/SPMSM as in [11]) and later modified in [12], belongs to this category. 
The fault-tolerant features of the topology are further elaborated in [13]. However, this work has several unresolved issues, namely: 1) the fault is assumed to be known a priori, therefore no detection and identification method is introduced yet; 2) the series switch fault is not included in the fault analysis. Therefore, in this paper the fault detection and identification method for an open switch fault in both the main and series switches is discussed. Furthermore, a novel normal and post-fault control strategy (being an adaptation of the one proposed in [13]) following a main/series switch fault is included. It is additionally shown in this paper that the novel control system allows for minimization of the current mismatch in case of winding parameters difference between the two windings of the same phase.

\section{Series-Connectable Modular Full-Bridge Inverter}

Fig. 1 depicts the single-phase two winding circuit of the series connectable modular full-bridge inverter. The index " $\mathrm{n}$ " denotes phase $\mathrm{a}$, b, or c. Machine windings are modelled by resistance $\left(R_{\mathrm{n} 1}\right.$ and $\left.R_{\mathrm{n} 2}\right)$, inductance $\left(L_{\mathrm{n} 1}\right.$ and $\left.L_{\mathrm{n} 2}\right)$, and back $\operatorname{EMF}\left(E M F_{\mathrm{n} 1}\right.$ and $\left.E M F_{\mathrm{n} 2}\right)$. The circuit parameters are shown in Table I.

There are three possible configurations in this circuit. The first configuration is called series configuration 1 by operating main switch $S_{\mathrm{n} 1}, S_{\mathrm{n} 2}, S_{\mathrm{n} 7}, S_{\mathrm{n} 8}$, and series switch $S_{\mathrm{sn} 1}$ as an H-bridge. Another H-bridge circuit is possible by operating main switch $S_{\mathrm{n} 3}, S_{\mathrm{n} 4}, S_{\mathrm{n} 5}, S_{\mathrm{n} 6}$, and series switch $S_{\mathrm{sn} 2}$, which is named series configuration 2 . The third one is named independent configuration by operating all main switches $\left(S_{\mathrm{n} 1}-S_{\mathrm{n} 8}\right)$ as two H-bridges and turning off all series switches.

In the previous work (see [10]) the reconfiguration from series to independent configuration was based on speed only (Fig. 2 left). However, it is suggested in [12] that the reconfiguration protocol based on modulation index turned out to be able to utilize fewer switching events for the same acceleration profile. Therefore, the reconfiguration based on modulation index is used throughout this paper (Fig. 2 right).

Table I: Circuit parameters for series connectable modular full-bridge inverter (the index "n" denotes the winding number).

\begin{tabular}{|c|c|c|}
\hline Parameters & Symbol & Value \\
\hline Voltage $(\mathrm{V})$ & $V_{\mathrm{dc}}$ & 320 \\
\hline Winding Resistance $(\Omega)$ & $R_{\mathrm{nx}}$ & 2.6 \\
\hline Winding Inductance $(\mathrm{mH})$ & $L_{\mathrm{nx}}$ & 33 \\
\hline Back EMF Constant $(\mathrm{Vs} / \mathrm{rad})$ & - & 1.91 \\
\hline
\end{tabular}

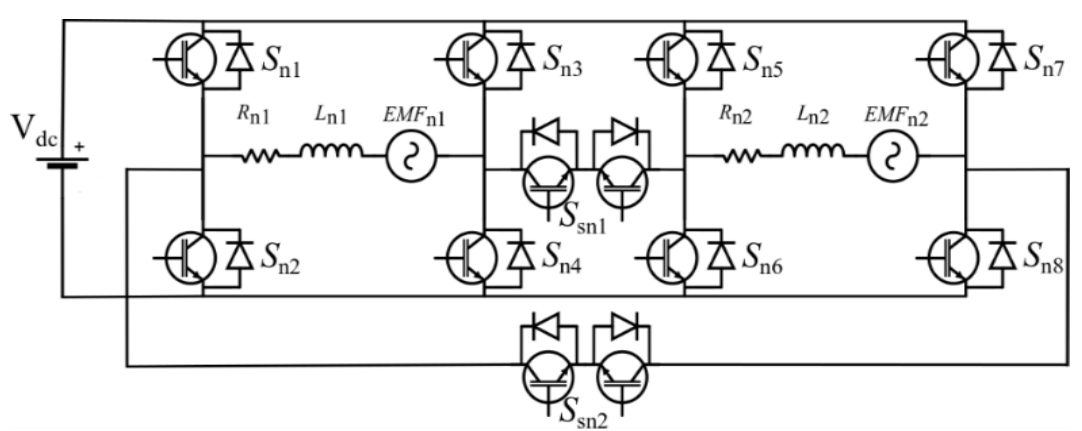

Fig. 1: Single-phase circuit of series-connectable modular full-bridge inverter. 

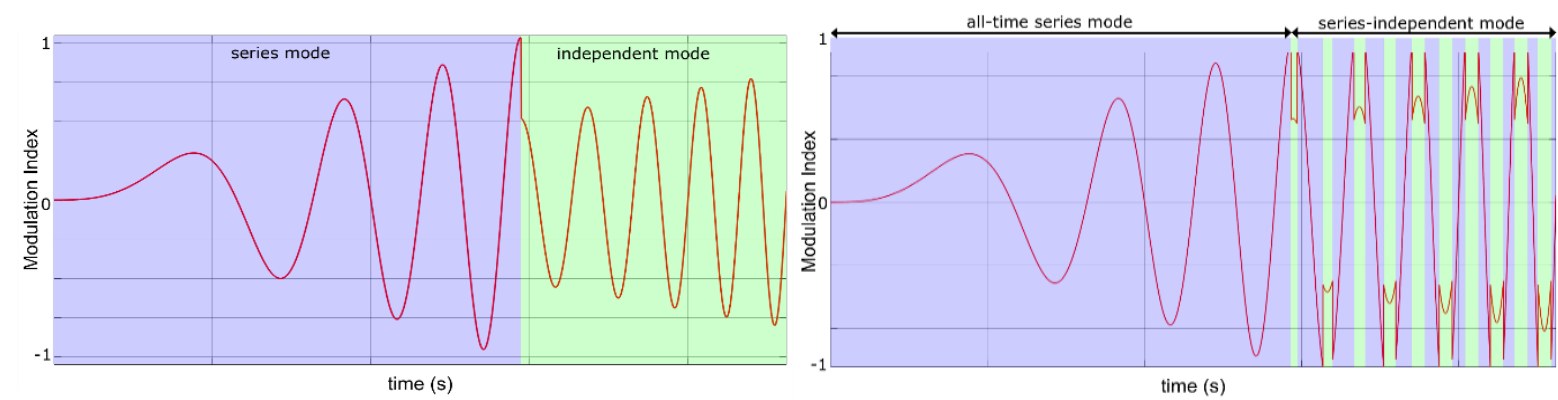

Fig. 2: Reconfiguration based on speed (left) and modulation index (right).

\section{A Novel Control Strategy in the Healthy Situation}

In [13] it is assumed that the current flowing to the two windings of the same phase are identical, as implied by showing the measurements of only three out of six windings currents. While this is unconditionally true in the series configuration, in independent configuration parameter differences between two windings of the same phase can cause a current mismatch. Therefore, in this paper a novel control strategy incorporating all the six windings currents is proposed to minimize the current mismatch in the independent configuration.

The idea is to reformulate the six phases current measurement to the sum and different parts which are decoupled from each other. This is realized by multiplying the measured currents $i$ by a decoupling matrix $T_{1}$, which is formulated as

$$
i_{\mathrm{abc}}^{\Sigma \Delta}=T_{1} i
$$

where

$$
i=\left[\begin{array}{c}
i_{\mathrm{a} 1} \\
i_{\mathrm{b} 1} \\
i_{\mathrm{c} 1} \\
i_{\mathrm{a} 2} \\
i_{\mathrm{b} 2} \\
i_{\mathrm{c} 2}
\end{array}\right] ; i_{\mathrm{abc}}^{\Sigma \Delta}=\left[\begin{array}{c}
i_{a}^{\Sigma} \\
i_{b}^{\Sigma} \\
i_{c}^{\Sigma} \\
i_{a}^{\Delta} \\
i_{b}^{\Delta} \\
i_{c}^{\Delta}
\end{array}\right] ; T_{1}=\left[\begin{array}{cccccc}
1 & 0 & 0 & 1 & 0 & 0 \\
0 & 1 & 0 & 0 & 1 & 0 \\
0 & 0 & 1 & 0 & 0 & 1 \\
1 & 0 & 0 & -1 & 0 & 0 \\
0 & 1 & 0 & 0 & -1 & 0 \\
0 & 0 & 1 & 0 & 0 & -1
\end{array}\right]
$$

The sum $\left(i_{\mathrm{abc}}^{\Sigma}\right)$ and difference $\left(i_{\mathrm{abc}}^{\Delta}\right)$ parts are decoupled from each other, and the respective parts each can be transformed from abc to $\alpha \beta 0$ coordinates by using the Clarke transformation $T_{2}$ :

$$
i_{\alpha \beta 0}^{\Sigma}=T_{2} i_{\mathrm{abc}}^{\Sigma} ; i_{\alpha \beta 0}^{\Delta}=T_{2} i_{\mathrm{abc}}^{\Delta}
$$

where

$$
T_{2}=\left[\begin{array}{ccc}
2 / 3 & -1 / 3 & -1 / 3 \\
0 & 1 / \sqrt{3} & -1 / \sqrt{3} \\
1 / 3 & 1 / 3 & 1 / 3
\end{array}\right]
$$

The $i_{\alpha \beta 0}^{\Sigma}$ and $i_{\alpha \beta 0}^{\Delta}$ parts are then transformed to dq0 coordinates by using Clarke-Park transformation $T_{3}$ :

$$
i_{\mathrm{dq} 0}^{\Sigma}=T_{3} i_{\alpha \beta 0}^{\Sigma} ; i_{\mathrm{dq} 0}^{\Delta}=T_{3} i_{\alpha \beta 0}^{\Delta}
$$

where

$$
T_{3}=\left[\begin{array}{ccc}
\cos \theta & \sin \theta & 0 \\
-\sin \theta & \cos \theta & 0 \\
0 & 0 & 1
\end{array}\right]
$$

and $\theta$ is the angular position of the rotor.

The $i_{\mathrm{dq} 0}^{\Sigma}$ and $i_{\mathrm{dq} 0}^{\Delta}$ parts are used as references for the vector control. The former is responsible for generating the torque and flux, while the latter for minimizing the current mismatches. For constant torque control, the references are generated as 


$$
\begin{aligned}
& i_{\mathrm{q}}^{\Sigma *}=\frac{2 K_{t}}{3} T_{\mathrm{em}}^{*} \\
& i_{\mathrm{d}}^{\Sigma *}=i_{0}^{\Sigma *}=i_{\mathrm{d}}^{\Delta *}=i_{\mathrm{q}}^{\Delta *}=i_{0}^{\Delta *}=0
\end{aligned}
$$

where $T_{\mathrm{em}}^{*}$ is the torque reference to be generated by the machine and $K_{t}$ is the machine constant.

The vector control then produces the voltage references for the sum $\left(v_{\mathrm{dq} 0}^{\Sigma *}\right)$ and difference $\left(v_{\mathrm{dq} 0}^{\Delta *}\right)$ parts. Both are transformed back to $\alpha \beta 0$ and then abc domain by using inverse Clarke-Park and inverse Clarke transformation, respectively. These are mathematically described as

$$
\begin{aligned}
& v_{\alpha \beta 0}^{\Sigma *}=T_{3}^{-1} v_{\mathrm{dq} 0}^{\Sigma *} ; v_{\alpha \beta 0}^{\Delta *}=T_{3}^{-1} v_{\mathrm{dq} 0}^{\Delta *} \\
& v_{\mathrm{abc}}^{\Sigma *}=T_{2}^{-1} v_{\alpha \beta 0}^{\Sigma *} ; v_{\mathrm{abc}}^{\Delta *}=T_{2}^{-1} v_{\alpha \beta 0}^{\Delta *}
\end{aligned}
$$

where

$$
T_{3}^{-1}=\left[\begin{array}{ccc}
\cos \theta & -\sin \theta & 0 \\
\sin \theta & \cos \theta & 0 \\
0 & 0 & 1
\end{array}\right] ; T_{2}^{-1}=\left[\begin{array}{ccc}
1 & 0 & 1 \\
-1 / 2 & \sqrt{3} / 2 & 1 \\
-1 / 2 & -\sqrt{3} / 2 & 1
\end{array}\right]
$$

Finally, the sum $\left(v_{\mathrm{abc}}^{\Sigma *}\right)$ and difference $\left(v_{\mathrm{abc}}^{\Delta *}\right)$ parts of the voltage are transformed back to generate the voltage reference in each phase by using the inverse sum-difference transformation $\left(T_{1}^{-1}\right)$. This is shown as

$$
\begin{aligned}
& v^{*}=T_{1}^{-1} v_{\mathrm{abc}}^{\Sigma \Delta *} \\
& T_{1}^{-1}=1 / 2\left[\begin{array}{cccccc}
1 & 0 & 0 & 1 & 0 & 0 \\
0 & 1 & 0 & 0 & -1 & 0 \\
0 & 0 & 1 & 0 & 0 & 1 \\
1 & 0 & 0 & -1 & 0 & 0 \\
0 & 1 & 0 & 0 & 1 & 0 \\
0 & 0 & 1 & 0 & 0 & -1
\end{array}\right] ; v^{*}=\left[\begin{array}{c}
v_{\mathrm{a} 1}^{*} \\
v_{\mathrm{b} 1}^{*} \\
v_{\mathrm{c} 1}^{*} \\
v_{\mathrm{a} 2}^{*} \\
v_{\mathrm{b} 2}^{*} \\
v_{\mathrm{c} 2}^{*}
\end{array}\right] ; v_{\mathrm{abc}}^{\Sigma \Delta *}=\left[\begin{array}{c}
v_{a}^{\Sigma *} \\
v_{b}^{\Sigma *} \\
v_{c}^{\Sigma *} \\
v_{a}^{\Delta *} \\
v_{b}^{\Delta *} \\
v_{c}^{\Delta *}
\end{array}\right]
\end{aligned}
$$

\section{Fault Description, Detection, and Identification}

The detection and identification of the main switch open fault is realized by comparing the PWM signal applied to the phase leg as a reference with the voltage measured between the phase node and the negative dc bus. This is shown in Fig. 3 (left) for the first leg, while the other legs are adapted accordingly. Under normal conditions, the difference generated is close to zero. When a switch is opened due to a fault, a difference between the reference and the measurement is generated. If the difference exceeds the positive value of the threshold $(\mathrm{K})$, the lower switch is registered as the faulty switch. If it exceeds the negative value of the threshold $(-\mathrm{K})$, the upper switch is registered as the faulty switch.

For the series switch, the phase node voltages of the two phase legs connected by the series switch are measured and their difference is compared with the reference (ideally zero). When the series switch sustains an open switch fault, there will be a difference between the two phase node voltages. If the value exceeds the threshold for the series switch fault detection $\left(\mathrm{K}_{\mathrm{s}}\right)$, the observed series switch is registered as the faulty switch. The overall procedure is shown in Fig. 3 (right) for $S_{\text {sn } 1 \text {, while the same }}$ method but with different observed legs is applied for $S_{\mathrm{sn2} 2}$. The moving average filter is used in the detection and identification method proposed to avoid a false alarm triggered by the dead time or ringing effect. 


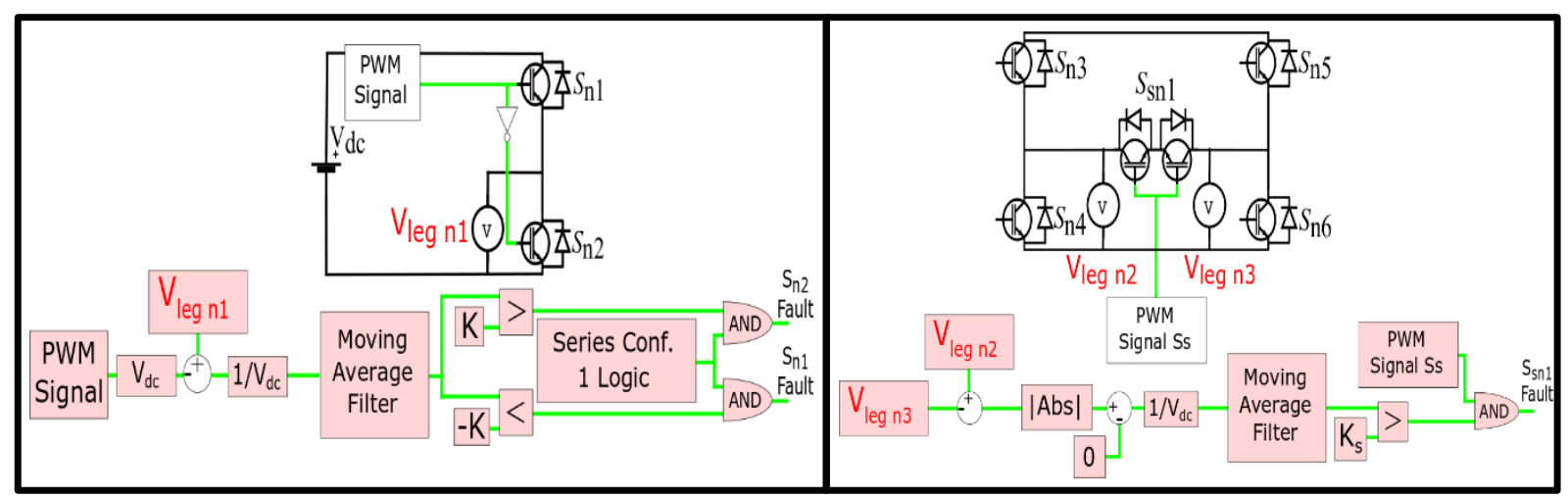

Fig. 3: Example of fault detection and identification method for the main (left) and series (right) switches.

The example of the detection output is presented in Fig. 4. The open switch fault is introduced in $0.3 \mathrm{~s}$. Here, the reconfiguration procedure is not included yet.
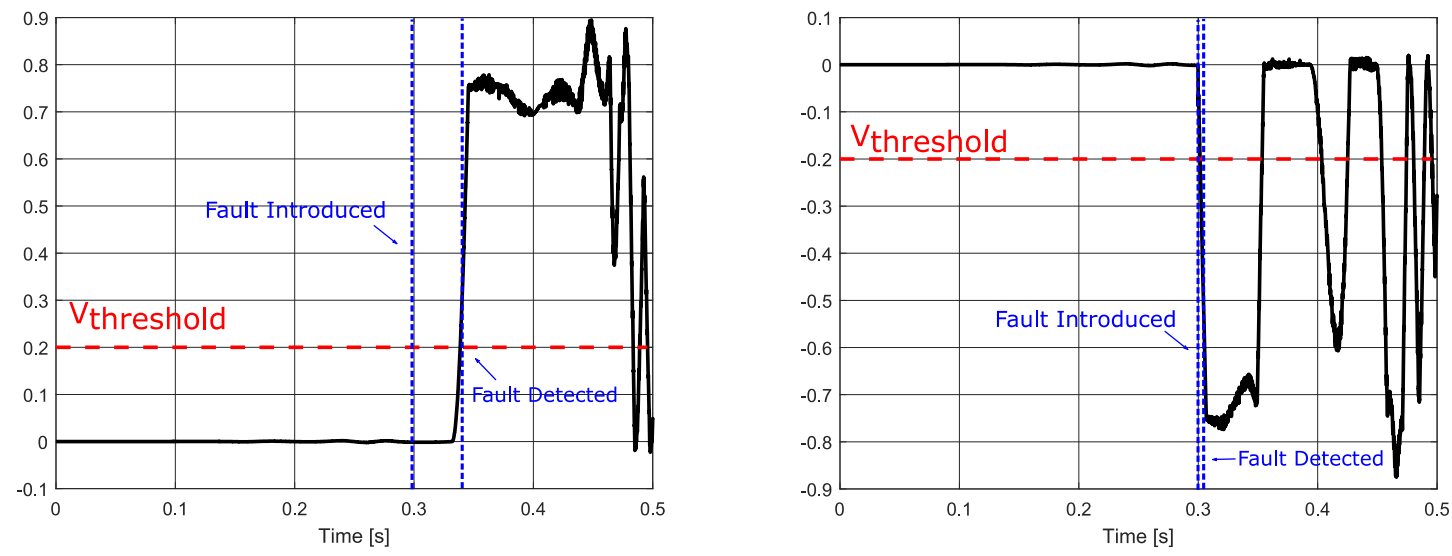

Fig. 4: Example of fault detection output signal at lower switch (left) and at upper switch (right)

In Fig.4, it is observed that the fault direction influences the detection process. Although the fault in both cases is introduced at the same time, the time response to the fault is different. It is due to the dependency of detection to the switching cycle of the converter, since the upper switch detection can only be done in the positive cycle of the current. As the reconfiguration duration target is $500 \mathrm{~ms}$ after a fault in order to accomplish system safety for a limp home condition, detection time within less than $50 \mathrm{~ms}$ is acceptable.

It is also shown that the detection procedure has a moving average filter. This is because in the switching event, a difference between the duty cycle and the normalized phase voltage measurement might occur due to the switching transient. Since on average the value is low, a moving average filter is added to avoid a false alarm in the case of switching event.

\section{Post-fault Control Reconfiguration}

The current phasor adaptation following a main switch fault is shown in Fig. 5. For example, if one of the main switches in $\mathrm{H}$-bridge a1 fails, that $\mathrm{H}$-bridge module is turned off. To achieve a new equilibrium, phase $b$ and c current phasor are shifted. 


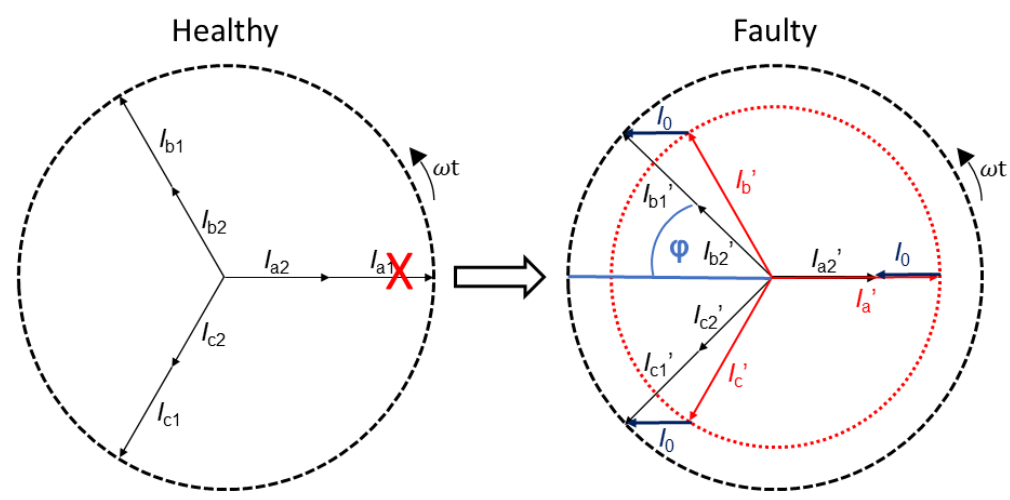

Fig. 5: Current phasor adaptation following a main switch fault.

From Fig. 5, the following equations are obtained [13]:

$$
\begin{aligned}
& 2 \sin \varphi=R \sin \pi / 3 \\
& 2 \cos \varphi+(1-R)=R \cos \pi / 3
\end{aligned}
$$

Where $R$ is the radius of the red circle, which leads to the post-fault operation with nominal current for the remaining phases. By solving (14) and (15), the values of $R$ and $\varphi$ are obtained as 1.618 and 0.776 $\mathrm{rad}$, respectively. The ratio of the red and black circles, which signifies the nominal torque in the faulty and healthy situations, is obtained as:

$$
\frac{T_{\text {faulty }}}{T_{\text {healthy }}}=\frac{1.618}{2}=0.809
$$

For $i_{\mathrm{a} 1}$ equal to zero and the torque reduction as in (16), the references for the $i_{\mathrm{dq} 0}^{\Sigma}$ and $i_{\mathrm{dq} 0}^{\Delta}$ are reformulated as follows

$$
\begin{aligned}
& i_{\mathrm{d}}^{\Sigma *}=0 \\
& i_{\mathrm{q}}^{\Sigma *}=\frac{R K_{t}}{3} T_{\mathrm{em}}^{*} \\
& i_{0}^{\Sigma *}=(1-R) i_{\mathrm{a} 2} \\
& i_{\mathrm{d}}^{\Delta *}=\frac{-2 i_{\mathrm{a} 2} \cos \theta}{3} \\
& i_{\mathrm{q}}^{\Delta *}=\frac{2 i_{\mathrm{a} 2} \sin \theta}{3} \\
& i_{0}^{\Delta *}=\frac{2 i_{\mathrm{a} 2}}{3}
\end{aligned}
$$

\section{Simulation Results and Discussion}

\section{Main Switch Fault}

Fig. 6 (left) shows the phase current in the abc domain, while Fig. 6 (right) shows it in the dq0 domain. It is shown in the abc domain that after the main switch $S_{\mathrm{a} 1}$ sustains an open switch fault, the current in winding a1 drops to zero and the phase angles of the remaining phases (b and c) are shifted to achieve the new equilibrium as depicted in Fig. 5. It is also shown in the dq0 domain that the quadrature current is reduced to $80.9 \%$ of its nominal value, i.e. from $45 \mathrm{~A}$ to $36.4 \mathrm{~A}$, confirming the analytical solution obtained in (16). It is also shown that in the post-fault control the zero-sequence current $\left(I_{0}\right)$ exists as a common-mode current. Fig.7 also shows the modulation index before and after the fault in the main switch $S_{\mathrm{a} 1}$, where it is shown that the $m_{\mathrm{a}}$ in the post-fault situation is half of the pre-fault situation one, 
since in independent operation only half of the modulation index is required to produce the same nominal current as in the series configuration one.
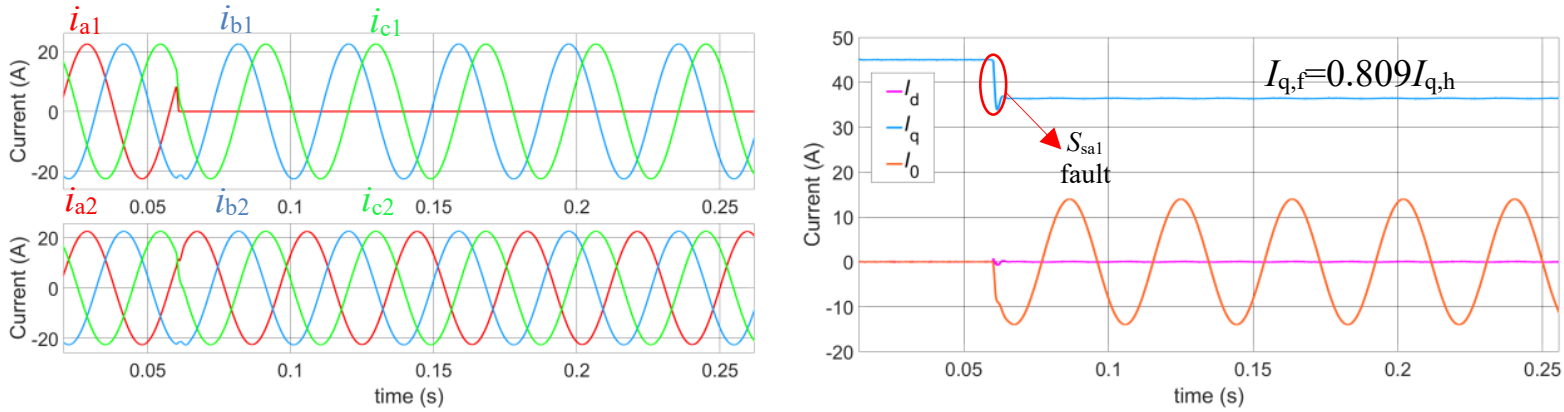

Fig. 6: Phase currents in abc domain (left) and dq0 domain (right).

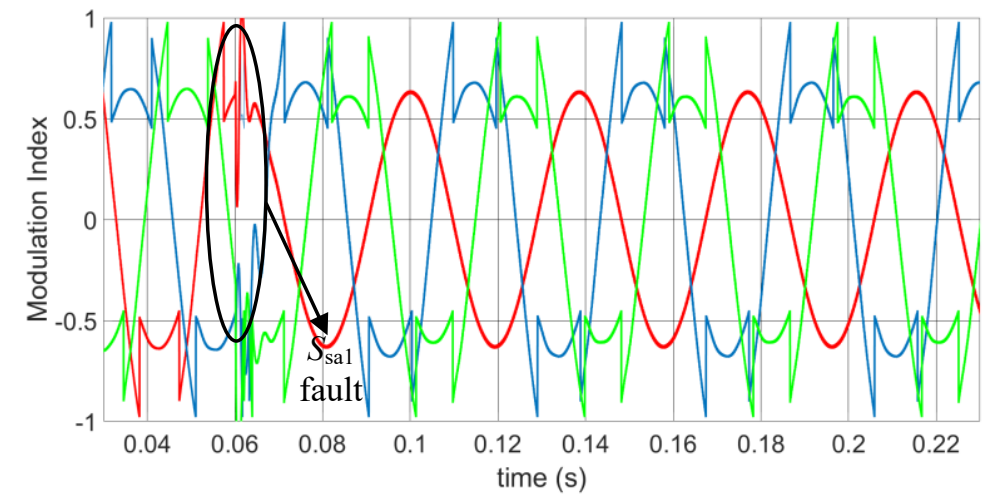

Fig. 7: Modulation index in the presence of a main switch $\left(S_{\mathrm{a} 1}\right)$ fault.
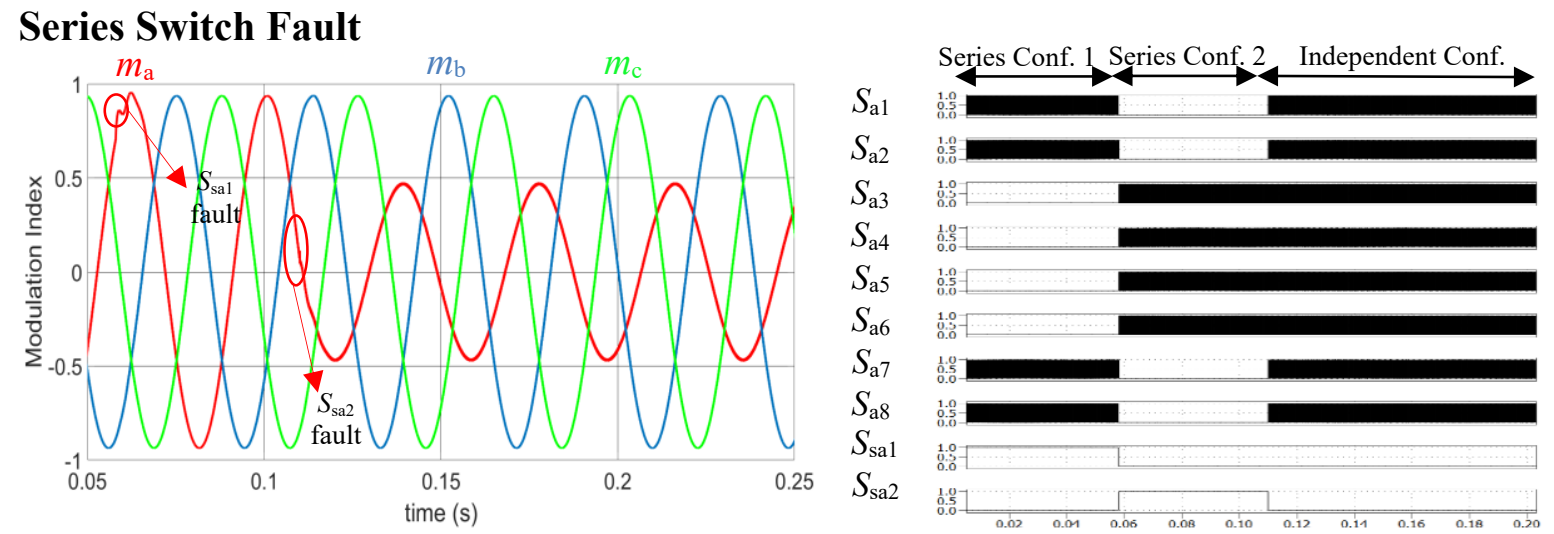

Fig. 8: Modulation index (left) and the PWM signals (right) in the presence of series switch faults.

Fig. 8 shows the modulation index of the circuit when a fault occurs at the series switches $S_{\mathrm{sa} 1}$ and $S_{\mathrm{sa} 2}$, sequentially. It is shown that when the fault is introduced at $S_{\text {sal }}(\mathrm{t}=0.058)$, the circuit changes from series configuration 1 to series configuration 2 . When another fault is introduced at $S_{\text {sa2 }}(t=0.11)$, the circuit continues operation in the independent configuration, as shown by the $m_{\mathrm{a}}$ being half of the original value in Fig. 8 (left). Fig. 8 (right) also shows the PWM signal of the phase a switches. 


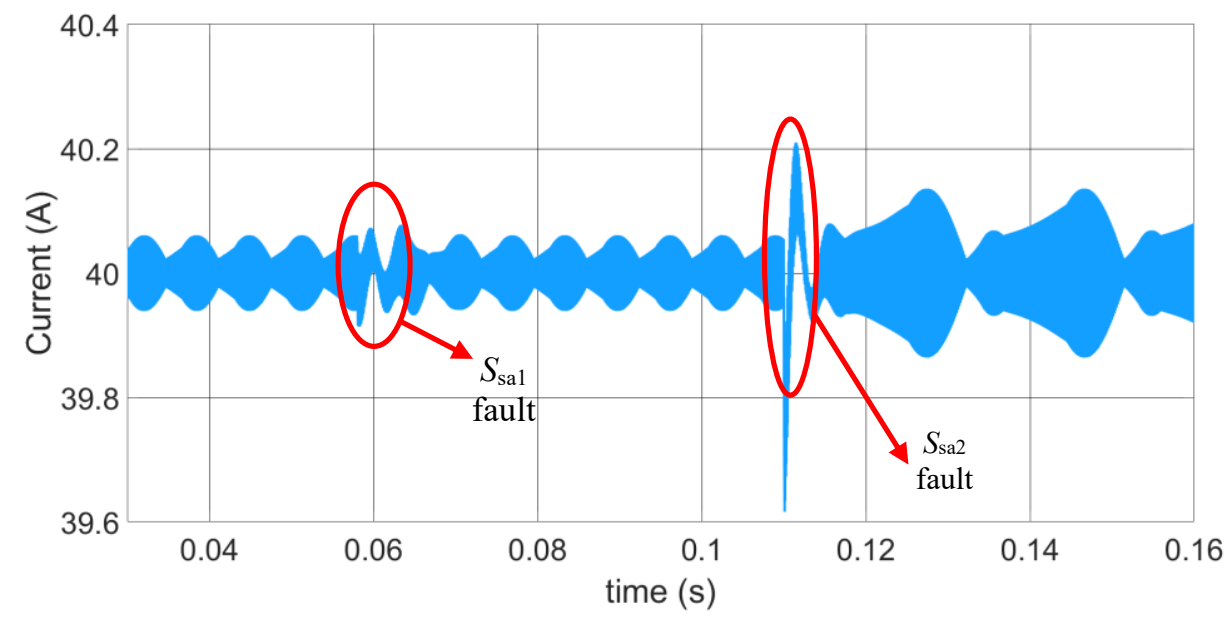

Fig. 9: Torque ripple in the series and independent configurations.

Fig. 9 shows the effect of the independent configuration on the torque ripple, as a result of the quadrature current behavior. It is shown that when phase a enters the independent configuration, the torque ripple is larger than in the series configuration. This is because in the independent configuration, the windings are driven individually. In this configuration, the total inductance has half the value of the series configuration one. Therefore, the current ripple in phase a is doubled, producing more torque ripple in the machine.

\section{The Effect of the Novel Control Strategy on the Current Mismatch}

Normally, only three out of six phases currents are needed for measurement, since the system runs on the multiple three-phase scenario. However, in the presence of parameter imbalance, in independent configuration a mismatch between two windings currents of the same phase can occur. Fig. 10 shows the mismatch between the currents in winding a 1 and a 2 when $R_{\mathrm{a} 2}$ is changed to be $95 \%$ of its original value $(2.6 \Omega)$ while the parameters in winding a2 are unchanged. $I_{\mathrm{q}}^{\Sigma *}$ is set to $60 \mathrm{~A}$.
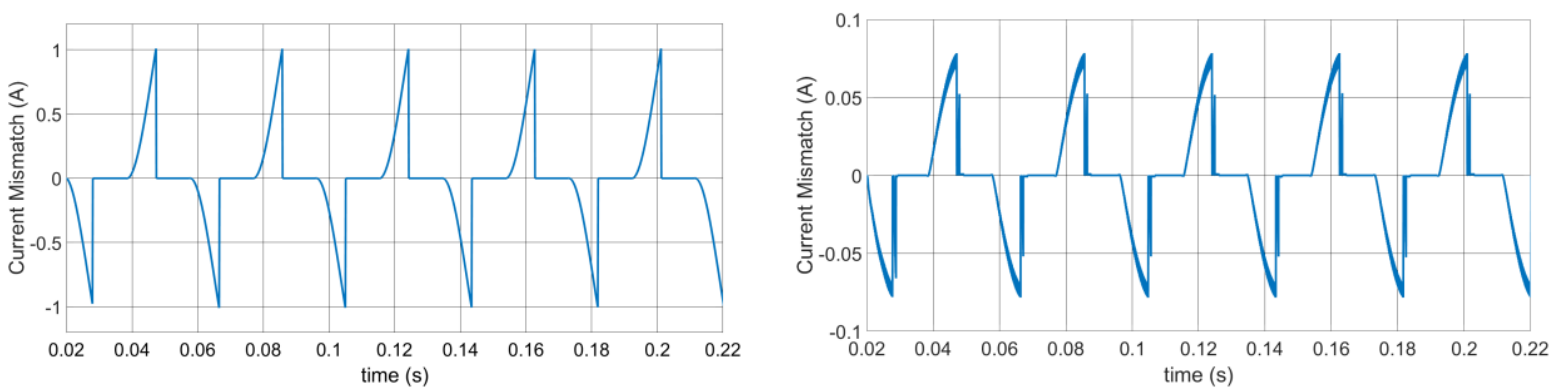

Fig. 10: Torque ripple in the series and independent configuration without (left) and with (right) the novel control strategy.

From Fig. 10, it is shown that the mismatch between the currents in winding a1 and a2 is greatly reduced when the novel control strategy is added. This is because of in the novel control strategy the difference part is also controlled, therefore minimizing the mismatch.

\section{Conclusion}

This paper discusses the fault detection, identification, and reconfiguration of the series connectable modular full-bridge inverter in the presence of a main or series switch fault. It is shown that in the presence of a main switch fault, the machine is able to produce $80.9 \%$ of its nominal torque. In the presence of a series switch(es) fault, the torque profile remains the same while more torque ripple is produced as the current ripple in the windings that are driven independently is approximately doubled. Additionally, it is shown that the novel control strategy can minimize the current mismatch of the windings of the same phase in case of parameter imbalance between the two windings. 


\section{References}

[1] A. Emadi, Y. J. Lee and K. Rajashekara, "Power Electronics and Motor Drives in Electric, Hybrid Electric, and Plug-In Hybrid Electric Vehicles," in IEEE Transactions on Industrial Electronics, vol. 55, no. 6, pp. 22372245, June 2008.

[2] B. A. Welchko and J. M. Nagashima, "The influence of topology selection on the design of EV/HEV propulsion systems," in IEEE Power Electronics Letters, vol. 1, no. 2, pp. 36-40, June 2003.

[3] S. Yang, A. Bryant, P. Mawby, D. Xiang, L. Ran, and P. Tavner, "An industry-based survey of reliability in power electronic converters," IEEE Transactions on Industry Applications, vol. 47, no. 3, pp. 1441-1451, May 2011.

[4] M. Held, P. Jacob, G. Nicoletti, P. Scacco and M. Poech, "Fast power cycling test of IGBT modules in traction application," Proceedings of Second International Conference on Power Electronics and Drive Systems, Singapore, 1997, pp. 425-430 vol.1.

[5] L. Wang, B. Vermulst, J. Duarte and H. Huisman, "Thermal stress reduction and lifetime improvement of power switches with dynamic gate driving strategy," EPE'19 ECCE Europe, Genova, 2019.

[6] L. Wei, J. McGuire and R. A. Lukaszewski, "Analysis of PWM Frequency Control to Improve the Lifetime of PWM Inverter," in IEEE Transactions on Industry Applications, vol. 47, no. 2, pp. 922-929, March-April 2011.

[7] C. H. van der Broeck, L. A. Ruppert, R. D. Lorenz and R. W. De Doncker, "Methodology for Active Thermal Cycle Reduction of Power Electronic Modules," in IEEE Transactions on Power Electronics, vol. 34, no. 8, pp. 8213-8229, Aug. 2019.

[8] B. A. Welchko, T. A. Lipo, T. M. Jahns and S. E. Schulz, "Fault tolerant three-phase AC motor drive topologies: a comparison of features, cost, and limitations," in IEEE Transactions on Power Electronics, vol. 19, no. 4, pp. 1108-1116, July 2004.

[9] B. Mirafzal, "Survey of fault-tolerance techniques for three-phase voltage source inverters,"IEEE Transactions on Industrial Electronics,vol. 61, no. 10, pp. 5192-5202, Oct 2014.

[10] T. Gerrits, C. G. E. Wijnands, J. J. H. Paulides and J. L. Duarte, "Electrical gearbox equivalent by means of dynamic machine operation," Proceedings of the 2011 14th European Conference on Power Electronics and Applications, Birmingham, 2011, pp. 1-10.

[11] T. Gerrits, J. L. Duarte, C. G. E. Wijnands, E. A. Lomonova, J. J. H. Paulides and L. Encica, "Twelve-phase open-winding SPMSM development for speed dependent reconfigurable traction drive," 2015 Tenth International Conference on Ecological Vehicles and Renewable Energies (EVER), Monte Carlo, 2015, pp. 1-7.

[12] B. Daniels, J. Gurung, H. Huisman and E. A. Lomonova, "Feasibility Study of Multi-Phase Machine Winding Reconfiguration for Fully Electric Vehicles," 2019 Fourteenth International Conference on Ecological Vehicles and Renewable Energies (EVER), Monte-Carlo, Monaco, 2019, pp. 1-6.

[13] T. Gerrits, C. G. E. Wijnands, J. J. H. Paulides and J. L. Duarte, "Fault-Tolerant Operation of a Fully Electric Gearbox Equivalent," in IEEE Transactions on Industry Applications, vol. 48, no. 6, pp. 1855-1865, Nov.-Dec. 2012. 